\title{
Visual braille and print reading as a function of display field size
}

\author{
THOMAS S. WALLSTEN \\ University of North Carolina, Chapel Hill, North Carolina 27514 \\ and \\ ROBERT M. LAMBERT \\ Concordia University, Montreal, Quebec H4B 1R6, Canada
}

\begin{abstract}
Highly experienced subjects read black-on-white braille and normal type within display fields 1,5 , or 15 characters in width. A second group of subjects read the same materials, but the braille was replaced by capital type of the same size. Reading rate differences between the braille and the type occurred that could be attributed to the processing of foveal rather than of peripheral information and that furthermore depended specifically on the discrete elemental vs. continuous line aspects of the two codes.
\end{abstract}

Skilled sighted adults normally achieve reading rates of from 200 to 700 or more words/min (wpm), with an average reading rate around $300 \mathrm{wpm}$ (Gibson \& Levin, 1975; Tinker, 1965). In contrast, skilled adult braille readers rarely exceed reading rates of $200 \mathrm{wpm}$, and the average is about $100 \mathrm{wpm}$ (Foulke, 1970). Somewhat lower braille reading rates are reported for high school children (Nolan \& Kederis, 1969). The difference in reading rates between braille and print is intriguing because it provides a possible means of exploring the role of sensory processing in reading. We think this exploration can be valuable, since most of the research on the determinants of skilled reading generally stresses psycholinguistic or cognitive factors (e.g., Brown, 1970; Gibson \& Levin, 1975, Chapter 10; Rozin \& Gleitman, 1977; Smith, 1971), yet the primary differences between print and braille are perceptual or sensory in nature. In contrast to print, braille is tactual, with no more than about two characters in view (covered by the fingers) at a time. In addition, the writing codes differ physically in that each braille cell is a rectangular 3 by 2 matrix, in which each location either contains a dot or does not, whereas print letters consist of continuous lines and curves. Although there are certain orthographic differences between the two codes, they both rely on the rules of English spelling and pronunciation. ${ }^{1}$

Of course, there is research investigating the role of pattern or letter recognition in reading (e.g., Brooks,

This research was supported by a grant from the Spencer Foundation. We thank the Blue Ridge Braillers of Asheville, North Carolina, and the Metrolina Association for the Blind of Charlotte, North Carolina, for their assistance, Mary Frances Eldridge and Robert Martin for preparing many of the braille materials and for their insights, and John B. Carroll, Samuel Fillenbaum, Sally Johnstone, Jack Loomis, Peter A. Ornstein, and Paul Shinkman for helpful comments.
1977; Kolers, 1976a, 1976b; Perfetti \& Lesgold, 1979), but we believe that comparisons between print and braille reading can be an important supplement to that work, because braille is a standard, widely used alphabet that differs from print in very fundamental ways. It is very likely that the standard modality difference between reading braille and print (tactual vs. visual) contributes to the rate differences, but in this study we used highly experienced sighted braille readers to eliminate the modality difference. All reading in this experiment was done visually.

Two groups of subjects were employed to determine how visual reading depends on the writing code, on the size of the display field, and on their interaction. Group 1 , experienced sighted braille readers, visually read both normal type and Grade 1 braille (see Footnote 1) through windows of different widths allowing 1,5 , or 15 characters to be seen simultaneously. Braille cells are approximately three times the size of standard lowercase type, but we decided to leave each code in its familiar state rather than equate visual angle. Instead, Group 2 was run in the same conditions except that the braille was replaced by text entirely in uppercase type equivalent in size to the braille cells. This condition served to control both for the greater visual angle of braille cells and for the fact that braille never extends above or below the line, as does lowercase type.

It is well established that both reducing the display field (Bouma \& De Voogd, 1974; McConkie \& Rayner, 1975; Newman, 1966) and enlarging the type to the degree that we did (Paterson \& Tinker, 1930, 1942) slows normal reading. The important question was whether the effects of display field size would differ between type and braille in a way that could not be attributed solely to differences in writing form size or word shape. More specifically, if Group 1 ratios (or 
differences) of normal type to braille reading rates were to match Group 2 ratios (or differences) of normal type to large capital reading rates, that would be explainable in terms of visual angle or word shape considerations. Dissimilar effects between the two groups would require an explanation in terms of the effective difference between the discrete elemental characteristics of braille and curvilinear aspects of print characters.

\section{METHOD}

\section{Subjects}

The 12 subjects in Group 1 were all experienced braille readers, having worked with braille from 1 to 14 years, with a mean of 6.5 years. Half the subjects obtained their experience by transcribing print to braille, and the other half as teachers of blind children and adults. None of the subjects could read braille tactually; they all read it visually. They ranged in age from 30 to 70 years, with a mean of 50 years, and all had normal or corrected-to-normal vision. Four subjects (two transcribers and two teachers) were assigned to each display field condition.

The 12 subjects in Group 2 were undergraduate college students, and all had normal or corrected-to-normal vision. Four subjects were assigned to each display field condition.

\section{Design and Materials}

Each group was run in a 2 by 3 (writing code by display field) design with repeated measures over the first factor. Each subject read paragraphs in normal type and in either braille or capital letter type through windows defining display fields one line high and 1,5 , or 15 characters wide. In order to hold contrast constant, the braille was prepared as black dots, not raised dots. The type was IBM Selectric Prestige Elite. Reading was done silently and timed with the aid of an apparatus that held the paper immobile and allowed the subject to move a window across the paper with his or her preferred hand. Each subject was assigned to a display field condition, and then he or she read three normal type and three braille or capital type practice paragraphs, followed by 20 paragraphs for data, either in the order of 5 normal type, 5 other, 5 normal type, 5 other, or in the reverse order.

More specifically, the apparatus was constructed so that the material to be read was held vertically $40 \mathrm{~cm}$ from the subject. When the subject moved the window all the way to the right margin, the paper began to move up one line and continued to do so as the window was being returned to the left margin. Thus, although regressions were allowed on a line, they were not allowed between lines. A timer was activated while the window was moving to the right and during regressions, but not while the paper was being advanced and the window was being returned to the left margin. Each paragraph ended in midsentence with a series of three green dots, which signaled the subject to stop reading and to choose the correct sentence ending out of four alternatives on the back of a card. Fluorescent lighting was such that white paper seen through a display field window had a luminance of $67 \mathrm{~mL}$. The normal print display fields of 1,5 , and 15 letters subtended horizontal visual angles of $.32,1.6$, and $4.7 \mathrm{deg}$, respectively, and a vertical visual angle of about $.29 \mathrm{deg}$. The braille and capital type fields of 1,5 , and 15 cells subtended horizontal visual angles of $.96,4.8$, and $14.2 \mathrm{deg}$, respectively, and a vertical visual angle of $.86 \mathrm{deg}$.

Reading material was taken from the SRA Reading for Understanding, Senior Kit (T. Thurstone, 1965). Each paragraph ends in midsentence, and as a comprehension check, the reader must select the correct sentence completion out of four alternatives. The paragraphs were all approximately equivalent in difficulty, as determined by previous scaling, and were divided into two equivalent sets of 10 paragraphs each.
The scaling was done using techniques described by L. L. Thurstone (1947). Basically, each paragraph was assigned a standard normal deviate score based on the adjusted percentage of respondents correctly completing it. We selected two groups of 10 paragraphs each, such that the mean score and standard deviation in Group A were 1.24 and .19 , respectively, whereas those in Group B were 1.20 and .23 , respectively. ${ }^{2}$ Each subject read one set of paragraphs in braille or capital type and one in normal type, with each paragraph set being read an equal number of times under each experimental condition by each group of subjects. Order of paragraphs was randomized over subjects. Comprehension, as measured by the sentence completion, was essentially perfect in all conditions.

\section{RESULTS}

In the absence of a well articulated model of reading, the choice of scale for measuring speed (or rate) is arbitrary. Since we do not have such a model and since effects observed with one variable may not appear in a nonlinear transformation of that variable, analyses were done on the following three measures: (1) speed, measured as minutes per word (mpw), (2) rate, the inverse of speed, measured as wpm, and (3) $\log _{10}$ wpm. Log rates convert reading rate ratios to differences and are equivalent except for a change of sign to log speeds.

Figure 1 shows mean $\log _{10}$ wpm for each group and writing code as a function of display field size; the latter is defined in terms of number of characters in the window in Panel A and in terms of the window's visual angle in Panel B. The other measures are not shown graphically, since it turned out that they all conveyed similar impressions. Reading rate increased with window size, was greater for the standard type than for either braille or large capital type, and was lowest overall for the braille.

For purposes of statistical analysis, each person was assigned difference scores equal to his or her reading measure given normal type minus his or her measure given braille or large capital type, for each of the three measures, mpw, wpm, and log wpm. The mean contrasts for each measure are shown in Table 1. Each set of contrasts was independently subjected to a fixedeffects analysis of variance (ANOVA) within the 2 by 3 design of Table 1. Overall, in all cases, the contrasts were significantly different from zero $(p<.001)$. As shown in Table 1, there was a significant effect of group (braille vs. capital) on contrast magnitude for all three measures and a significant effect of display field size on contrast magnitude for log wpm and wpm, but not for mpw. In no case was there a significant Group by Display Field Size interaction.

\section{DISCUSSION}

We presented the statistical analysis on mpw for completeness, but we feel that it is vitiated by the extreme heterogeneity of variance. Therefore, this measure will not be discussed further.

The remaining findings are summarized simply: Figure 1 demonstrates that $\log$ reading rate increases with window size for all writing forms studied (and so does arithmetic reading rate). From the ANOVAs, we conclude that there are statistically 


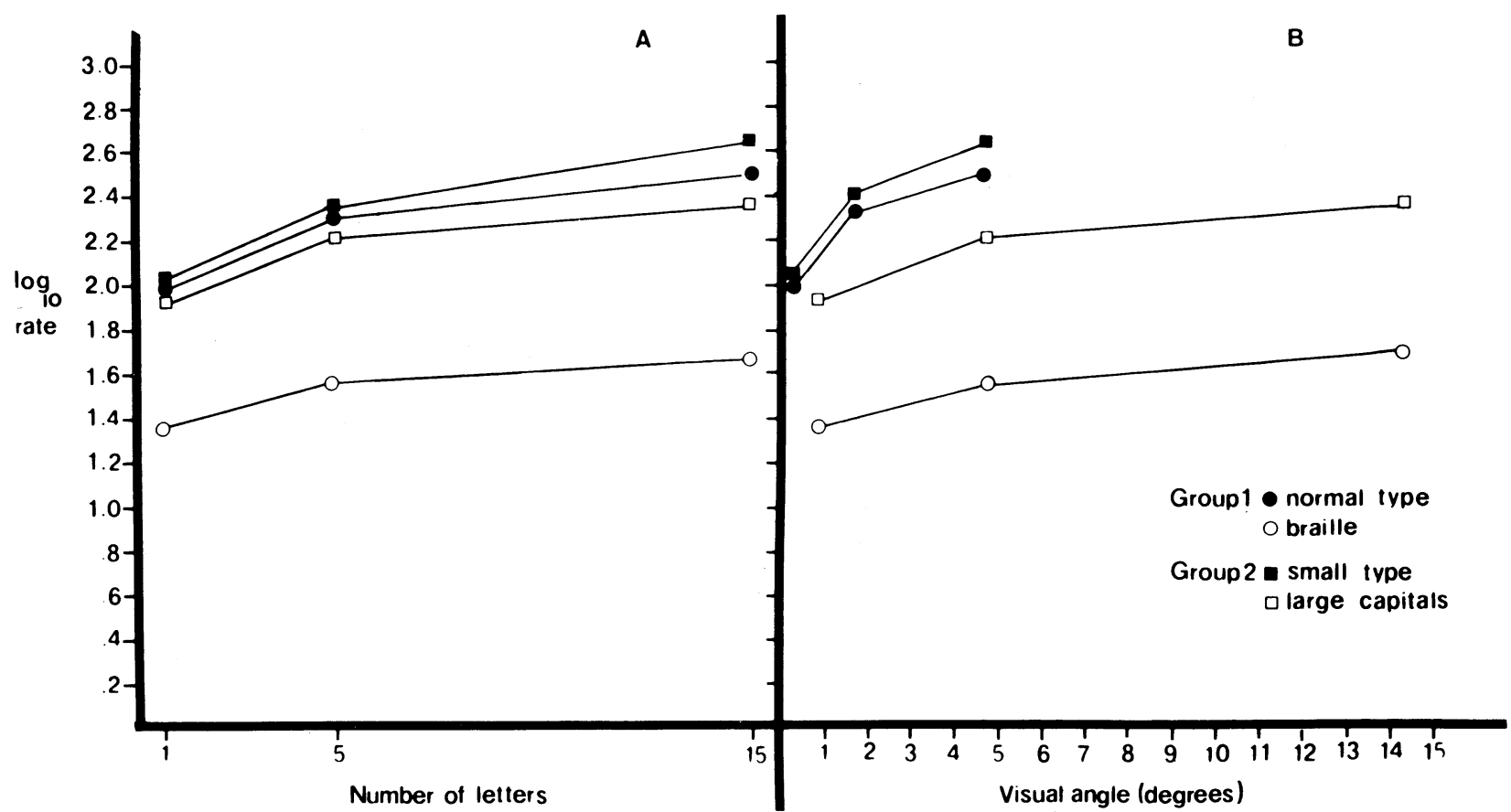

Figure 1. Mean $\log _{10}$ reading rates as a function of (A) number of characters in the display field and (B) visual angle of the display field, shown separately for group and writing form.

significant differences in $\log$ and in arithmetic reading rates between the large- (braille or capital type) and small-character writing forms, that the differences are significantly greater when the large form is braille than when it is capital type, and that the differences increase with window size.

The fact that the contrast between small- and large-form rates increases with number of simultaneously available characters is easily explained. As the number of characters in the window increases, the concomitant change in visual angle is smaller for normal type than for the large forms. Hence, acuity degradation is less pronounced, and therefore, reading rate grows faster in the former than in the latter condition.

Actually, the above argument is too simple, because recognition threshold size for letters increases with retinal eccentricity (Anstis, 1974), and this factor must be considered when comparing acuity degradation for letters of different sizes at different retinal locations. ${ }^{3}$ Anstis (1974) determined that recognition threshold letter height increases approximately linearly with retinal eccentricity, up to an eccentricity of $30 \mathrm{deg}$. Utilizing the linear regression equation reported by Anstis, the large symbols (braille or large capital) at the far right of the five-character window are estimated to be 4.52 times the recognition threshold height, assuming fixation at the left edge of the display field, whereas the corresponding small symbols are approximately
7.25 times recognition threshold height. ${ }^{4}$ For the 15 -character windows, the large and small symbols are estimated to be $\mathbf{1 . 3 9}$ and 1.53 times threshold, respectively. Thus, for both the 5and 15-character windows, the larger symbols at the peripheral edge of the display fields are relatively closer to threshold than are the smaller symbols. Therefore, acuity degradation with increase in display field size is more severe in the former than in the latter case, as suggested in the previous paragraph.

Consider, now, the other main effect, due to group, shown in Table 1 for the wpm and log wpm contrasts. The fact that braille contrasts with normal type more than does capital type requires us to consider possible differences attributable to the discrete elemental vs. curvilinear features of the two writing forms. It will be useful to distinguish between the processing of foveal and of peripheral information in understanding these differences. Thus, $t$ tests demonstrate that there is a significant braille/normal type contrast $[\mathrm{t}(3)=14.42, \mathrm{p}<.001]$ at the onecharacter window, whereas there is a nonsignificant large capital/ normal type contrast $[t(3)=2.59, p>.05]$. These results suggest a braille/normal type difference in processing of foveal information. If there were also a deficit in processing peripheral information for braille over and above that for capital type, then one should expect the braille contrasts to grow more rapidly with window size than do the capital type contrasts. The lack of

Table 1

Means and Standard Deviations of Contrasts Between Normal Type and Either Braille or Large Capital Type as a Function of Display Field Size, Plus ANOVA F Ratios

\begin{tabular}{|c|c|c|c|c|c|c|c|c|c|c|c|c|c|c|c|}
\hline & \multicolumn{4}{|c|}{ Display Field Size 1} & \multicolumn{4}{|c|}{ Display Field Size 5} & \multicolumn{4}{|c|}{ Display Field Size 15} & \multicolumn{3}{|c|}{$F$} \\
\hline & \multicolumn{2}{|c|}{ Braille } & \multicolumn{2}{|c|}{ Capital } & \multicolumn{2}{|c|}{ Braille } & \multicolumn{2}{|c|}{ Capital } & \multicolumn{2}{|c|}{ Braille } & \multicolumn{2}{|c|}{ Capital } & \multirow[b]{2}{*}{ G } & \multirow[b]{2}{*}{ D } & \multirow{2}{*}{$\begin{array}{c}G \text { by } \\
\text { D }\end{array}$} \\
\hline & Mean & SD & Mean & SD & Mean & SD & Mean & SD & Mean & SD & Mean & SD & & & \\
\hline $\log _{10} W P M$ & .62 & .09 & .07 & .05 & .72 & .19 & .11 & .04 & .81 & .22 & .27 & .12 & $102.86 \dagger$ & $3.84^{*}$ & .14 \\
\hline WPM & 80.90 & 35.50 & 17.00 & 16.20 & 155.90 & 47.90 & 47.70 & 18.80 & 263.90 & 102.20 & 218.80 & 134.00 & $5.80^{*}$ & $14.56 \dagger$ & .39 \\
\hline MPW × 10 & -.37 & .20 & -.02 & .01 & -.24 & .10 & -.01 & .01 & -.19 & .06 & -.02 & .01 & $39.83 \dagger$ & 1.82 & 1.72 \\
\hline
\end{tabular}

Note $-\log _{10}$ MPW contrasts are the negative of $\log _{10} W P M$ contrasts. $G=$ group (braille vs. capital); $D=$ display field size (1 vs. 5 vs. 15). ${ }^{*} p<.05 . \quad t p<.001$. 
a significant ANOVA interaction for the data of Table 1 suggests that this was not the case; rather, the two contrasts increased at equivalent rates. Thus, we conclude that braille and capital type appear to differ uniformly from normal type in terms of effective useful peripheral information, for the reasons discussed above, and that braille differs from both print forms only in the use of foveal information.

It is not surprising that peripheral information contributes equally to reading rates for large capital type and braille. At least informally, word length appears to be equally discriminable in the two cases, and that is apparently the only information obtained from the periphery that affects reading (McConkie \& Rayner, 1975; Rayner, 1978).

Why do braille and type differ in foveal processing? Experience is a possible, but we think unlikely, explanation. Subjects with 12 to 14 years experience using the 5- and 15-character windows achieved rates only between 45 and $70 \mathrm{wpm}$. Based on anecdotal accounts, people often learn and read intermittently in new alphabets, such as Hebrew, Russian, or Arabic, yet achieve reading rates well in excess of these within a much shorter period of time. In addition, there is no reason to believe that experience would have an effect on foveal rather than peripheral processing. It would appear that there is something uniquely suited about the curvilinear aspects of normal writing.

Although we do not currently have a satisfactory explanation for the foveal difference between print and braille, it is clear that a complete account of the reading process will require models of pattern recognition that either are specialized for the writing form employed or can accommodate the particular writing form.

It is interesting to speculate in this regard that perhaps the discrete elemental nature of braille provides insufficient or less than optimal stimulation of the receptive fields of feature detectors, which would respond more fully to lines than to dots. As a result, the feature detection commonly a part of vision, and thus employed in letter identification, is hampered in the fovea when looking at braille, resulting in slower identification of braille than of type.

\section{REFERENCES}

American Association of Workers for the Blind, AssoCiation for Education of the Visually Handicapped, \& the National Braille Association. English braille American edition, 1959. Louisville, Ken: American Printing House for the Blind, 1972.

Anstis, S. M. A chart demonstrating variations in acuity with retinal position. Vision Research, 1974, 14, 589-592.

Bouma, H., \& DEVoogd, A. H. On the control of eye saccades in reading. Vision Research, 1974, 14, 273-284.

Brooks, L. Visual pattern in fluent work identification. In A. S. Reber \& D. L. Scarborough (Eds.), Toward a psychology of reading. Hillsdale, N.J: Erlbaum, 1977.

Brown, R. Psychology and reading: Commentary on Chapters 5 to 10. In H. Levin \& J. P. Williams (Eds.), Basic studies in reading. New York: Basic Books, 1970.

Foulke, E. Non-visual communication VIII: Reading by touch. Education of the Visually Handicapped, 1970, 2, 87-88.

Gibson, E. J., \& LEvin, H. The psychology of reading. Cambridge, Mass: M.I.T. Press, 1975.

Kole rS, P. A. Pattern analyzing memory. Science, 1976, 191, 1280-1281. (a)

Kolers, P. A. Reading a year later. Journal of Experimental Psychology: Human Learning and Memory, 1976, 2, 554-565. (b)
McConkie, G. W., \& Rayner, K. The span of the effective stimulus during a fixation in reading. Perception \& Psychophysics, $1975,17,578-586$.

Newman, E. B. Speed of reading when the span of letters is restricted. American Journal of Psychology, 1966, 79, 272-278.

Nolan, C. Y., \& Kederis, C. J. Perceptual factors in braille word recognition. New York: American Foundation for the Blind, 1969.

Patterson, D. G., \& Tinker, M. A. How to make type readable. New York: Harper \& Row, 1930.

Patterson, D. G., \& Tinker, M. A. Influence of size of type on eye movements. Journal of Applied Psychology, 1942, 26, 227-230.

Perfetti, C. A., \& Lesgold, A. M. Coding and comprehension in skilled reading and implications for reading instruction. In L. B. Resnick \& P. Weaver (Eds.), Theory and practice in early reading. Hillsdale, N.J: Erlbaum, 1979.

RAYNER, $K$. Eye movements in reading and information processing. Psychological Bulletin, 1978, 85, 618-660.

Rozin, P., \& Gleitman, L. R. The structure and acquisition of reading II: The reading process and the acquisition of the alphabetic principle. In A. S. Reber \& D. L. Scarborough (Eds.), Toward a psychology of reading. Hillsdale, N.J: Erlbaum, 1977.

Sм ітн, F. Understanding reading. New York: Holt, 1971.

Thurstone, L. L. The calibration of test items. American Psychologist, 1947, 2, 103-104.

Thurstone, T. Reading for understanding (Senior Kit). Chicago, Ill: Science Research Associates, 1965.

Tinker, M. A. Bases for effective reading. Minneapolis, Minn: University of Minnesota Press, 1965.

\section{NOTES}

1. More specifically, each dot in a braille cell is $1.1 \mathrm{~mm}$ in diameter and center-to-center dot separation is $2.5 \mathrm{~mm}$. Thus a cell is a $6.1 \times 3.6 \mathrm{~mm}$ rectangle. Adjacent cells are spaced such that neighboring columns have center-to-center dot separations of $3.8 \mathrm{~mm}$. The six possible dot locations yield $2^{6}-1=63$ possible cell configurations, which make up the entire universe of braille symbols. There are two common orthographies in braille. Grade 1 braille is more or less isomorphic to print, in that every word is spelled out in full. In addition, composition symbols are used to indicate capitals, numbers, italics, and so on. Thirty-two of the 63 configurations are used in Grade 1. Grade 2, or "English braille," includes Grade 1, but also contains 189 contractions or short-form words and incorporates the remaining 31 symbols (see American Association of Workers for the Blind, Association for Education of the Visually Handicapped, \& the National Braille Association, 1972).

The sparse evidence that exists suggests that reading rates do not differ markedly for Grades 1 and 2 braille (Nolan \& Kederis, 1969), which, if correct, is interesting in its own right.

2. We thank Thelma Thurstone for making available to us the unpublished difficulty scaling she did.

3. We thank Jack Loomis for drawing our attention to the Anstis (1974) paper.

4. The last value should not be taken too seriously, however, since the linear equation probably underestimates the true threshold near the fovea, due to the negative intercept probably caused by sampling error.

(Received for publication November 19, 1980.) 